\title{
The effects of paid family leave on food insecurity- evidence from California
}

\section{Otto Lenhart $\mathbb{D}^{1}$}

Received: 7 April 2020 / Accepted: 11 December 2020 / Published online: 7 January 2021 (C) The Author(s) 2021; This article is published with open access

\begin{abstract}
This study examines the relationship between the 2004 introduction of California's paid family leave (PFL) program on food security. While previous work has shown that PFL laws affect employment, poverty and health, there is no evidence so far whether such policies affect food security levels of families after the birth of a child. Estimating difference-in-differences (DD) and triple difference (DDD) models, this is the first study to evaluate potential effects on food security, which could be a potential mechanism explaining improvements in health outcomes for both infants and mothers found in previous studies. My analysis shows that California's PFL implementation reduced the incidence of very low household food security by 2.29 (DD) and 1.98 percentage points (DDD) in the year following a birth. I find that the effects are driven improvements in food security among children who are 1.41 percentage points less likely to be food insecure after the PFL introduction. Subgroup analysis shows that the effects are largest for low-income households, a group that has been shown to highly value PFL benefits, as well as for families with more than one child.
\end{abstract}

Keywords Paid family leave $\cdot$ Food insecurity $\cdot$ Childbirth $\cdot$ California

JEL codes $\mathrm{J} 18 \cdot \mathrm{J} 38 \cdot \mathrm{I} 38$

\section{Introduction}

The United States is the only developed country without a national paid family leave (PFL) program for parents following the birth of a child. Starting with California in 2004, four states have so far introduced PFL, while nine states have enacted PFL

Otto Lenhart

ottolenhart@gmail.com

1 Department of Economics, Strathclyde Business School, University of Strathclyde, Duncan Wing, 199 Cathedral Street, Glasgow, Scotland, UK 
programs. Nonetheless, only 17 percent of working people in the U.S. have access to paid family leave through their employer, with this proportion being even lower for low-income workers (U.S. Bureau of Labor Statistics 2018). Research on California's PFL shows that, in addition to affecting poverty rates (Stanczyk 2019) and maternal labor market outcomes (Byker 2016; Das and Polachek 2015), the program also provides health benefits for both children (Lichtman-Sadot and Pillay Bell 2017; Pihl and Basso 2019) and mothers (Bullinger 2019). Less is known how PFL impacts other outcomes of well-being, which could potentially be mechanisms related to improvements in labor market and health outcomes. This study adds to our understanding of the effects of PFL laws by examining whether California's PFL improved household food security rates.

While other developed countries have national PFL policies in place, no previous study has examined the relationship between these laws and food insecurity. PFL provisions could reduce food insecurity among families following the birth of a child by providing financial protection, avoiding unemployment, allowing parents to smooth their consumption and increasing parental engagement for a longer period. This study evaluates the effects of PFL laws on food and nutritional security following childbirth. In 2014, more than 20.9 percent of U.S. households with children were defined as food-insecure by the U.S. Department of Agriculture (USDA), whereas $1.2 \%$ of households had very low food security. Using data from the Current Population Survey Food Security Supplement for the years 1999-2007, I estimate difference-in-differences (DD) models to measure whether California's PFL law improved food security of families after the birth of a child. In line with previous work on California's PFL program (Bullinger 2019; RossinSlater et al. 2013), I use three different control groups to obtain a series of DD estimators. Additionally, I estimate triple difference (DDD) models that take into account potential within-state differences in food insecurity among families with older children, a group that should have not been largely affected by the PFL implementation.

My analysis provides evidence that California's PFL program significantly reduced food insecurity among households following childbirth. Using all other states as the control group, I find that the policy implementation reduced the incidence of household experience very low food security by 2.29 and 1.98 percentage points in the DD and DDD analysis, respectively. These effects are robust to the choice of control group and several measures of food security. I find that the effects are driven by improved food security among children. When evaluating whether the policy change had heterogeneous impacts, I find that the effects are stronger for low-income households, a group that has been shown to highly value PFL benefits (Winston et al. 2017), as well as families with more than one child and those with parents under the age of 30. A placebo test and an alternative DD specification provide further evidence that the observed effects are driven by the PFL law. In line with previous research on the implementation of California's PFL law, the findings of this study also make the case that PFL programs have unintended positive effects on food security levels of families with infants. 


\section{Background}

Besides the U.S., all other developed countries have national policies in place ensuring that households receive paid support following the birth of a child. In 2018, the average total length of paid maternity and parental leave provided by non-U.S. OECD countries is 55 weeks, whereas the average wage replacement rate during the leave period is 63 percent among these countries (OECD 2019).

\subsection{Parental leave in the United States}

Until the enactment of the Family and Medical Leave Act (FMLA) of 1993, the U.S. did not provide any benefits related to maternal leave. The nationwide policy requires employers of 50 or more workers to provide at least 12 weeks of unpaid maternity leave with guaranteed health insurance after the birth or adoption of a child. Furthermore, mothers must have worked at least $1250 \mathrm{~h}$ in the past 12 month to be eligible for leave. Ruhm (1998) and Han et al. (2009) show that these strict requirements lead to only around half of employees are eligible for FMLA leave, with eligibility rates substantially lower among less-educated and unmarried mothers.

Eight states (California, New Jersey, Rhode Island, New York, Washington, Massachusetts, Connecticut, and Oregon) and D.C. currently have laws in place that mandate paid family leave. Table 1 provides an overview of the differences between the PFL policies in these states. It is noticeable that they differ in their lengths, wage replacement rates, and maximum benefits. Furthermore, while the remaining states provide job protection, California, New Jersey, Washington and D.C. only guarantee job protection if leave is taken under FMLA simultaneously.

This study evaluates California's 2004 PFL program, the first state-wide program that was implemented in the U.S., on food security rates among families following childbirth. The PFL law guaranteed 6 weeks of leave paid at 60 or $70 \%$ of pre-leave wages to parents in California (see Table 1). Parents are eligible to receive benefits if they are working or actively looking for work at the beginning of the leave period, while having at least $\$ 300$ in earnings during the year prior to leave. ${ }^{1}$ Studying the effects of California's program can be informative in understanding the effects of similar programs in other states or a potential future national PFL policy. Proposals for a national paid maternity leave program in the U.S., also known as the FAMILY Act, have been presented to Congress every year since 2013. Despite much support, these proposals have not yet led to any enactment of federal policy. Table 1 shows that PFL policies in other states are longer and in some cases more generous than California's provision. This suggests that findings for improvements in food security following in California following the implementation of the policy might be a lower bound estimate for more recent PFL laws in other states.

\footnotetext{
1 Birth mothers in California were already eligible to take maternity leave under the state's Disability Insurance program. Bana et al. (2018) estimate that over $80 \%$ of birth mothers who make a PFL claim also make a DI claim for the same birth.
} 


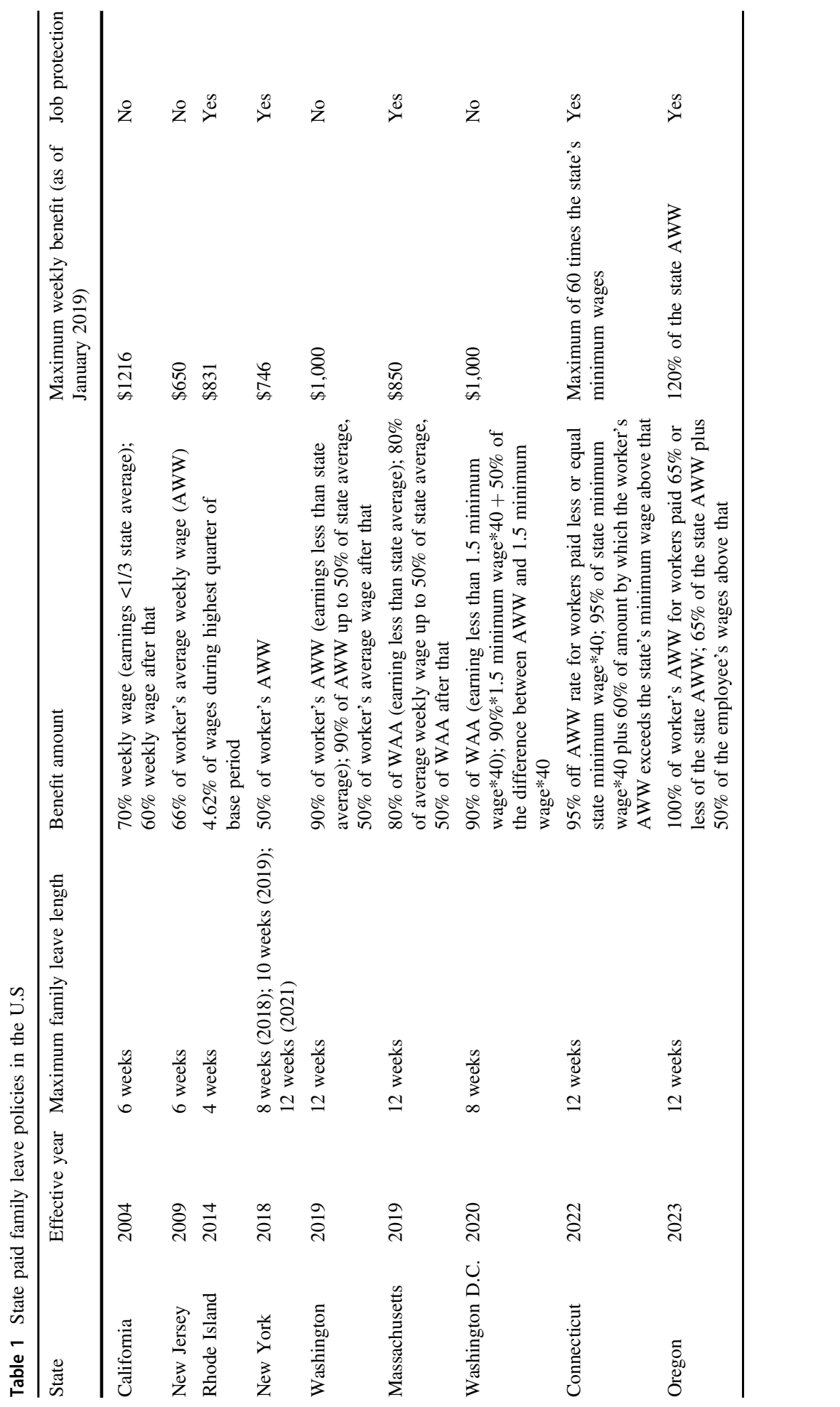




\subsection{Food insecurity research}

Food insecurity rates in the U.S. have grown continuously from 2000 until the end of the Great Recession. Despite improvements in the state of the economy following the crisis, food insecurity rates have remained higher than prior to the Great Recession for 41 states (Schanzenbach et al. 2016), with 14\% of all U.S. households and 19\% of those with children experiencing food insecurity in 2014 (Coleman-Jensen et al. 2015). The persistent high share of families in the U.S. experiencing food insecurity over the last decade can significantly affect the well-being of society. Previous research has shown that food insecurity is associated with negative nutritional outcomes for adults (Bhattacharya et al. 2004) and adverse health effects for adults and children (Gundersen and Kreider 2009; Gundersen et al. 2011).

Researchers have previously evaluated the role of various income assistance policies in reducing food insecurity. A large number of papers have studied the association between nutrition programs and food insecurity (Gundersen and Oliveira 2001; Gundersen and Kreider 2008, 2009; Nord and Golla 2009; Mykerezi and Mills 2010; Gundersen et al. 2011; Nord and Prell 2011; Ratcliffe et al. 2011; Kreider et al. 2012). Existing research on the effects of non-food safety net programs on food insecurity is substantially smaller. Examining a range of programs covering cash and food assistance as well as public health insurance, Schmidt et al. (2016) find that $\$ 1000$ in potential benefits reduces the incidence of food insecurity by 1.1 percentage point on a base of 33 percent among low-income single families.

Two studies on the Earned Income Tax Credit (EITC) provide suggestive evidence that the increases in the generosity of the program are likely to be affect food insecurity. Lenhart (2019) shows that the expansion of the EITC in the 1990s increased total household expenditures on food, while McGranahan and Schanzenbach (2013) provide evidence that EITC benefits are associated with more spending on healthy food products. Schmidt et al. (2016) also suggest that the effect of nonfood programs and nutrition programs may depend on how they interact each other. For example, increases in the generosity of income assistance might reduce the benefit levels for food assistance programs (Ziliak et al. 2003).

\subsection{Parental leave and food insecurity}

This study adds to the existing research evaluating the effects of non-food government programs on food insecurity by examining PFL laws. PFL laws can affect the food security of families following the birth of a child through several pathways. First, it has been shown that, compared to taking unpaid maternal leave, receiving paid leave benefits provides financial protection and allows families to smooth household earnings after childbirth (Rossin-Slater et al. 2013; Stanczyk 2019). Stanczyk (2019) shows that the introduction of California's PFL decreases the risk of poverty for mothers of 1-year olds by $10.8 \%$ in subsequent years. Rose et al. (1998) find that impoverished households are 3.5 times more likely to be food insufficient. In contrast to unpaid leave, the availability of additional family resources following childbirth allows parents to spend more money on childrearing. Additionally, a reduction in stress related to their financial situations may prevent parents from 
having to make large sacrifices in terms of their own food consumption in order to ensure that their child can eat sufficiently. ${ }^{2}$

Second, PFL laws can reduce food insecurity rates by affecting employment outcomes of parents following childbirth. Prior work examining the determinants of food insecurity has shown that unemployment has significant effects on food security levels of both parents and children (Nord 2007, 2009). Similarly, Huang et al. (2015) provide evidence that both the number of unemployment spells and the duration of unemployment significantly increase the risk of food insecurity. Previous evidence on the effects of California's PFL on employment has found mixed evidence. Baum and Ruhm (2016) find that California's PFL raised employment of mothers by about $23 \% 1$ year after childbirth, and increased work during the child's second year of life by $11 \%$. In contrast, Das and Polachek (2015) and Bailey et al. (2019) find that the policy had negative of zero effects on employment.

Third, PFL policies can affect food security by altering the behavior of parents in ways that increase the well-being of their children. Related to the afore-mentioned increases in employment, previous work has also established that PFL laws increase the length of maternity leave taken (Rossin-Slater et al. 2013; Baum and Ruhm 2016). Findings in the literature suggest that parental leave laws also affect parental engagement. For example, by taking additional paid parental leave, children's wellbeing may improve through increased time spent breastfeeding, more consistent attendance to well-child medical visits, and increased receipt of necessary immunizations compared to scenarios where mothers take very short unpaid leaves (Kamerman 2006).

Improved food security may be a mechanism through which PFL improves health outcomes of both children and parents. While two previous studies have shown that food insecurity is associated with a decline in health and poor nutritional outcomes (Gundersen and Ziliak 2015; Reis 2012), recent work has established that the implementation of California's PFL program had positive effects on the health of children and mothers (Bullinger 2019; Lichtman-Sadot and Pillay Bell 2017; Pihl and Basso 2019). Schwarzenberg and Georgieff (2018) argue that nutrition in the first 2 years of life are crucial for a child's neurodevelopment and lifelong mental health, while also affecting the risk of obesity, hypertension, and diabetes among both children and parents. This study examines the role of food security as a potential channel underlying the association between PFL programs and health outcomes of affected households.

\section{Data}

This analysis uses data from the Food Security Supplement (CPS-FSS), an annual supplement to the Current Population Survey that is conducted by the U.S. Census Bureau. The CPS-FSS is a nationally representative household survey, which interviews household twice for 4 months each, with a 8 month break in between. The survey contains detailed information on household-level food security in addition to

\footnotetext{
${ }^{2}$ It should however also be noted that PFL has also been shown to increase leave-taking duration and therefore also can also have potential negative effects on income.
} 
providing demographic information on respondents and their households. This study uses data for the period 1999-2007, with the sample restricted to individuals with children in the household. ${ }^{3}$ The main analysis evaluates outcomes for families whose youngest child is aged less than one year. In additional specifications, households where the youngest child is between ages 4 and 6 are added to the analysis as comparison groups given that these families were not affected by the California PFL policy.

The CPS-FSS includes a set of 18 questions on food security, which apply to the respondent's household as a whole. The questions cover information on whether individuals are concerned about insufficient food budget or food supply, inadequate food quality, and consequences of food reduction for adults and children. Questions 1-10 are related to adult food security status, while questions 11-18 are linked to child food security status. ${ }^{4}$ The full set of questions is shown in the Appendix. Using the number of affirmative responses, my analysis uses five different measures to capture potential changes in food insecurity experienced by households in the previous 12 months. ${ }^{5}$ The main outcome variable is very low food security, which the USDA defines as having at least eight affirmative responses (Bickel et al. 2000). My analysis uses a dichotomous indicator for very low food security, which is in line with previous studies examining determinants of food security in the U.S. (e.g., Anderson et al. 2016; Chilton et al. 2014; Nord 2007). The next two measures estimate the effects on the likelihood experiencing either low or very low food security. To explore which household members are suffering from food insecurity, I use separate measures for food insecurity for adults and children living in the household for these two outcomes. ${ }^{6}$ The final two measures used in the analysis are the food insecurity gap, which was introduced by Dutta and Gundersen (2007) and has been applied in prior work on food insecurity (Gundersen 2008; Moellman 2020). The food insecurity gap fully utilizes the richness of the eighteen question asked in the CPS-FSS. The gap is computed, I convert affirmative responses to all questions into a single indicator using the Rasch scoring method, which measures the probability of a household providing an affirmative response depending on the degree of food insecurity captured by the question. This allows me to create an index that measures how far a food insecure household is from the food security threshold (i.e., three for low food security and eight for very low food security). The two food insecurity gap that I use in my analysis are the normalized distances from the respective food security threshold. Following Dutta and Gundersen (2007), all

\footnotetext{
${ }^{3}$ Ending the sample period in 2007 assures that the observed estimates are not driven by the onset of the Great Recession in 2008, which increased food insecurity across the United States (Schanzenbach et al. 2016). While the CPS-FSS was fielded at different months before 2001, when it became fixed in December. In additional placebo test analyses, I include earlier years starting from 1996.

${ }^{4}$ Since all households in the sample have children, I am able to use all 18 questions asked in the CPS-FSS.

${ }^{5}$ Responses of "yes", "often", "sometimes", "almost every month", and "some months but not every month" are coded as affirmative (Bickel et al. 2000).

${ }^{6}$ Adult food insecurity uses the first ten questions of the CPS-FSS. According to the USDA, low adult food security is defined by at least three affirmative responses out of these ten questions (Nord and Bickel 2002). Child food insecurity uses questions 11-18 of the CPS-FSS. According to the USDA, low child food security is defined as at least two affirmative responses for these eight question (Nord and Bickel 2002).
} 
households obtain a vale between zero and one based on their food insecurity ( 0 representing food security).

The estimated regressions control for a set of individual and household variables, such as parent's age and number of children in the household (both continuous variables) as well as race, marital status, employment status, and completed level of education (all dummy variables). To account for the fact that food security levels are likely influenced by local economic conditions (Nord et al. 2014), I additionally include annual state unemployment and poverty rates (Bullinger 2019).

\section{Methods}

This study estimates both DD and DDD specifications to evaluate the effects of California's PFL law on food insecurity. Additionally, I conduct several robustness checks to provide suggestive evidence for the validity of the assumptions of the DD and DDD models used in the main analysis.

\subsection{DD model}

In the main model of the analysis, I compare changes in food security among families with the youngest child less than 1 year of age in California (treatment group) with families whose youngest child is $<1$ year of age living in states that are unlikely to be affected by California's PFL implementation (control group). Equation (1) below shows the main DD equation estimated in this study:

$$
\begin{aligned}
\mathrm{Y}_{\text {ist }}= & \beta_{0}+\beta_{1} \mathrm{CA}_{\text {ist }}+\beta_{2} \mathrm{POST}_{\mathrm{t}}+\delta_{\mathrm{DD}} \mathrm{POST}_{\mathrm{t}} * \mathrm{CA}_{\mathrm{is}}+\beta_{3} \mathrm{X}_{\mathrm{it}}+\beta_{4} \mathrm{Z}_{\mathrm{st}}+\lambda_{1} \text { Year }_{\mathrm{t}} \\
& +\lambda_{2} \text { State }_{\mathrm{s}}+\varepsilon_{\text {ist }},
\end{aligned}
$$

where $\mathrm{Y}_{\text {ist }}$ is an indicator that equals one if respondent i's household suffers from very low food security in year $t$ and state $s . \mathrm{CA}_{\mathrm{is}}$ is an indicator for whether an individual resides in California, while $\mathrm{POST}_{\mathrm{t}}$ equals one if the interview is held in the years after the policy change (2005-2007). The main parameter of interest is $\delta_{\mathrm{DD}}$, which captures the effect of the PFL introduction on very low food security. Given the nature of the data used in the analysis, this corresponds to the intent-to-treat (ITT) effect. $\mathrm{X}_{\mathrm{it}}$ represents a set of baseline individual and household controls such as age, gender, race, marital status, employment status, the number of children living in the household, and completed level of education. The inclusion of $\mathrm{Z}_{\mathrm{st}}$ accounts for timevarying state-level controls, which include annual state unemployment and poverty rates. Additionally, Eq. (1) controls for year and state fixed effects to account for unobservable differences in food insecurity rates across time and space. ${ }^{7}$ All regression use unweighted.

\footnotetext{
${ }^{7}$ All results shown in the paper are obtained from regressions using unweighted CPS IPUMS data. The results remain unchanged when weighting the regressions by sampling weights provided in the data.
} 
Closely following previous work evaluating the effects of California's PFL implementation (Bullinger 2019; Rossin-Slater et al. 2013), my analysis uses three different control groups when estimating Eq. (1). The first control group includes households with a child $<1$ year of age in all states other than California, whereas the other two control groups include other large states (Florida, New York, Pennsylvania, and Texas) and neighboring states (Arizona, Oregon, Nevada, Washington). As mentioned by Bullinger (2019), neighboring states might be the ideal control group if climate and environmental factors are the most important influences on food security, while other large states might be the better control group if large and diverse economies play a more crucial role. Additionally, the use of large states as the control group might mitigate concerns related to potential migration to California following the PFL introduction due to the inherent geographic distance between California and these other large states. Finding that the DD estimates are robust across the use of different control groups furthermore lends support that the DD "parallel trends" assumption is satisfied (Bullinger 2019).

Due to the small number of clusters, I follow the analysis by Bullinger (2019) and apply the wild cluster bootstrap resampling method with 1000 replications proposed by Cameron et al. (2008). Cameron et al. (2008) show that standard asymptotic tests can over-reject the null in the presence of only a few clusters and introduce an alternative method to account for within-group dependence when estimating standard errors. When using all other U.S. states as the control group, I use Rademacher weights as suggested by Cameron et al. (2008). For the models with fewer than 12 clusters (large and neighboring states as control groups), I implement a 6-point distribution as introduced by Webb (2014), which allows for improved inference with few clusters.

\subsection{DDD model}

Despite robustness of the DD estimates across different control groups, food security trends might have still been different in California and in other states in the absence of the PFL implementation. For example, if other changes during the sample period differentially affected financial security of households with children in California compared to the other U.S. states, the DD specifications could provide biased estimates. One way to test for the presence of this bias is to additionally estimate DDD models that take into account within-state differences and include households with children that should not be affected by PFL laws in the same way as families with infants but could potentially be affected by other state-level changes or trends in food security. In line with this, Rossin-Slater et al. (2013) show that California's PFL implementation had no effect on leave taking among families with older children. While there could potentially be spillover effects on families with older children, these effects should be substantially smaller than for families with newborns. Thus, I include households with the youngest child being between 4 and 6 years of age as an additional comparison group in the DDD model. Specifically, I estimate the 
following equation:

$$
\begin{aligned}
& \mathrm{Y}_{\mathrm{ist}}=\beta_{0}+\beta_{1} \mathrm{CA}_{\mathrm{ist}}+\beta_{2} \mathrm{POST}_{\mathrm{t}}+\beta_{3} \mathrm{INFANT}_{\mathrm{ist}}+\beta_{4} \mathrm{POST}_{t} * \mathrm{CA}_{\mathrm{is}} \\
& +\beta_{5} \mathrm{POST}_{\mathrm{t}} * \mathrm{INFANT}_{\mathrm{is}}+\beta_{6} \mathrm{INFANT}_{\text {ist }} * \mathrm{CA}_{\mathrm{st}} \\
& +\delta_{\mathrm{DDD}} \mathrm{POST}_{t} * \mathrm{INFANT}_{\mathrm{i}} * \mathrm{CA}_{\mathrm{s}}+\beta_{7} \mathrm{X}_{\mathrm{ist}}+\beta_{8} \mathrm{Z}_{\mathrm{st}}+\lambda_{1} \text { Year }_{t}+\lambda_{2} \text { State }_{\mathrm{s}}+\varepsilon_{\text {ist }}
\end{aligned}
$$

where INFANT is an indicator that equals one if the youngest child in the household is below age 1 and zero if the youngest child in the household is between 4 and 6 . While all other variables remain the same as in Eq. (1), the main parameter of interest for estimating Eq. (2) is $\delta_{\mathrm{DDD}}$. Finding that the DD and DDD effects are similar would remove concerns that the DD results are potentially biased due to different food security trends during the period of the study that are unrelated to the introduction of California's PFL policy.

\subsection{Robustness checks}

The estimation of DD and DDD models in order to obtain causal estimates comes with two main identifying assumptions. In the context of this study is that the PFL implementation is uncorrelated with other time-varying determinants of food security. Furthermore, valid DD designs assume that the control group is a suitable counterfactual for the treatment group. One way to provide evidence for this assumption is to test for parallel pre-trends. I conduct five types of robustness checks to lend support for the assumptions of the analysis.

First, I conduct a placebo analysis for the time periods 1996-2003 for all three control groups and estimate both DD and DDD specifications using an artificial policy change on January 1, 2000. Given that there were no changes in PFL laws during these years, any statistical significant differences across treatment and control states would suggest that the presence of differential trends between the two groups during the pre-treatment period of the main analysis. Finding no differences between the groups in these placebo tests would furthermore provide evidence that the control groups are suitable counterfactuals for the treatment group and remove concerns that other changes are potentially driving the main effects.

Second, I conduct an event analysis to capture annual treatment effects and to further test for the validity of the parallel trend assumption of the DD and DDD analysis. This is in line with recent work on food insecurity by Moellman (2020). The event study approach estimates the following equation:

$$
\begin{aligned}
\mathrm{Y}_{\text {ist }}= & \beta_{0}+\beta_{1} \mathrm{CA}_{\text {ist }}+\beta_{2} \text { POST }_{\mathrm{t}}+\sum_{(t=1996)}^{2007} \delta_{t} \text { Year }_{\mathrm{t}} * \mathrm{CA}_{\mathrm{is}}+\beta_{3} \mathrm{Xit}+\beta_{3} \mathrm{Z}_{\mathrm{st}} \\
& +\lambda_{1} \text { Year }_{\mathrm{t}}+\lambda_{2} \text { State }_{\mathrm{s}}+\varepsilon_{\text {ist }}
\end{aligned}
$$


where the year indicators (Year ${ }_{t}$ ) are interacted with the indicator for living in the treatment state California. In order to have more pre-treatment observations, I use the years 1996-2007 in the event study analysis. The excluded reference category is the first year of the analysis (1996).

Third, in order to account for potentially different trends between treatment and control groups during period of interest, I re-estimate an alternative DD model based on Mora and Reggio (2019). DD models require an assumption that trends in the variable of interest are similar for both treatment and control groups in the absence of the policy change. This assumption implies that without the treatment, differences between the groups are assumed to be time-invariant. Mora and Reggio (2019) point out that the identification of the treatment effect does not only depend on the parallel trends assumption, but also on the trend modelling strategy applied by researchers. For example, the authors show that DD estimates will differ substantially depending on whether group-specific linear trends or group-specific, time-invariant linear trends are included in the analysis in order to accommodate for trend differentials between treatment and control groups. By arguing that researchers often overlook this fact, Mora and Reggio (2019) introduce an alternative DD estimator, which identifies the effect of the policy using a fully flexible dynamic specification and includes a family of alternative parallel growth assumptions. This alternative DD model is estimated in two steps (Mora and Reggio 2019): first, standard least-squares estimation of the fully flexible model is conducted, and second, the solution of the equation in differences identifies the estimates. ${ }^{8}$ The two main advantages the authors list in favor of their DD estimate are that it: (1) allows for flexible dynamics and for testing restrictions on these dynamics; (2) does not impose equivalence between alternative parallel assumptions. Estimating this alternative model can lend support for the validity of standard DD assumptions if the results are in line with the main DD estimates.

Fourth, I test whether California's policy change was correlated with other timevarying determinants of food insecurity to remove concerns about interpreting the main DD and DDD estimates as causal effects. In separate specifications, I reestimate Eqs. (1) and (2) using the control variables of the main analysis as the dependent variables. Finding no statistically significant effects of California's PFL policy on age, the total number of children living in the household, education, race and state unemployment rates would provide further evidence for the validity of both the DD and the DDD design.

Fifth, to further lend support for the parallel trends assumption of the DD model, I estimate an alternative model. Using data for the pre-policy years (1999-2003) only, I create a variable that equals zero for California and one for all other states as well as an interaction term between the "non-California" dummy variable and a linear time trend. An indicator for food insecurity remains the dependent variable, with all regular control are included in the specification. Thus, the coefficient on the interaction term indicates whether the pre-treatment time trend in food insecurity differs between California and the other states and provides evidence for the validity of the DD specification.

\footnotetext{
${ }^{8}$ Computation of the standard errors of the treatment effect estimates takes into account that the solution of the equation in differences is a linear combination of the parameters of the fully flexible model.
} 


\subsection{Descriptive statistics}

Table 2 provides descriptive statistics of the samples used in the analysis, with the statistics showing information for both the survey respondents and their households. Based on general demographics, such as age, gender, race, marital status and total number of children, respondents with children under one year of age in California (treatment group) are relatively similar to individuals forming the three control groups. The statistics show that the share of treated households with very low food security decreased following California's PFL introduction, whereas food security decreased for all three control groups. Table 2 also shows statistics for the incidence of either low or very low food security among adults and children. The statistics for California (treatment group) suggest that food insecurity decreased among children, while remaining slightly increasing among adults. ${ }^{9}$

Table 2 Descriptive statistics for survey respondents (1999-2007)

\begin{tabular}{|c|c|c|c|c|}
\hline Variable & Treatment group & $\begin{array}{l}\text { Control group } 1 \\
\text { (All states) }\end{array}$ & $\begin{array}{l}\text { Control group } 2 \\
\text { (Large states) }\end{array}$ & $\begin{array}{l}\text { Control group } 3 \\
\text { (Neighboring states) }\end{array}$ \\
\hline Age & $31.13(6.97)$ & $30.04(6.54)$ & $30.39(6.65)$ & $29.51(6.75)$ \\
\hline Male & $0.46(0.50)$ & $0.45(0.50)$ & $0.45(0.50)$ & $0.45(0.50)$ \\
\hline White & $0.82(0.38)$ & $0.84(0.36)$ & $0.84(0.36)$ & $0.87(0.34)$ \\
\hline Married & $0.80(0.40)$ & $0.79(0.41)$ & $0.80(0.40)$ & $0.76(0.42)$ \\
\hline \# of Children & $2.08(1.12)$ & $2.03(1.12)$ & $2.06(1.14)$ & $2.01(1.08)$ \\
\hline HS degree or less & $0.49(0.50)$ & $0.43(0.49)$ & $0.46(0.50)$ & $0.50(0.50)$ \\
\hline Working & $0.60(0.49)$ & $0.65(0.64)$ & $0.64(0.48)$ & $0.61(0.49)$ \\
\hline Unemployment rate & $5.60(0.67)$ & $4.76(1.12)$ & $5.03(0.84)$ & $5.47(1.14)$ \\
\hline Poverty rate & $12.99(0.49)$ & $11.55(2.96)$ & $13.62(2.37)$ & $11.48(1.87)$ \\
\hline \multicolumn{5}{|c|}{ Very low food security } \\
\hline Pre & $0.04(0.18)$ & $0.02(0.14)$ & $0.02(0.13)$ & $0.04(0.19)$ \\
\hline Post & $0.02(0.15)$ & $0.03(0.17)$ & $0.03(0.16)$ & $0.04(0.20)$ \\
\hline \multicolumn{5}{|c|}{ Low/very low food security—adults } \\
\hline Pre & $0.11(0.32)$ & $0.11(0.31)$ & $0.10(0.30)$ & $0.16(0.36)$ \\
\hline Post & $0.12(0.08)$ & $0.11(0.31)$ & $0.11(0.31)$ & $0.11(0.31)$ \\
\hline \multicolumn{5}{|c|}{ Low/very low food security-children } \\
\hline Pre & $0.08(0.27)$ & $0.06(0.23)$ & $0.05(0.22)$ & $0.06(0.25)$ \\
\hline Post & $0.06(0.24)$ & $0.05(0.22)$ & $0.05(0.22)$ & $0.05(0.22)$ \\
\hline Observations & 2073 & 23,077 & 4146 & 1606 \\
\hline
\end{tabular}

\footnotetext{
9 Descriptive statistics by subgroups reveal that the share of families with low/very low food security in California decreased even more for households below $185 \%$ of the poverty line and for those with more than one child, two groups with higher than average food insecurity rates overall.
} 


\section{Results}

\subsection{Main results}

Table 3 presents the main estimates of the analysis. For all DD (Panel A) and DDD (Panel B) specifications, I find that the introduction of California's PFL law reduced the incidence of very low food security among families with children $<1$ year of age. Column (2) shows a 2.29 percentage point $(p<0.01)$ reduction in very low food security for the DD specification with all states as the control group. This corresponds to a $64 \%$ reduction compared to the pre-2004 sample mean for the treatment group. The DD estimate remains similar for the other two control groups. While being similar in magnitude, the effects for control group 3 (neighboring states) are statistically insignificant, which is likely related to a small sample size for this DD model.

Panel B provides evidence that the negative effects of California's PFL law remain when estimating DDD models, which suggest that the observed treatment effects are not driven by other within-state differences that are related to food security rates of families with children. When using all states as the control group, the magnitude of the effects is slightly smaller in magnitude, whereas the estimates remain statistically significant at the 1 percent level. The similarity of the DD and DDD results removes concerns that the DD results might be biased due to other potential changes during the study period. Furthermore, the results remain unchanged when including state-specific linear time trends to control for trends within states over time. ${ }^{10}$ While the DD specification (Panel A) is the preferred model since it narrows the sample to families with infants, the DDD results in Panel B show that the effects are robust to additionally accounting for differences in food security trends across treatment and control states that are unrelated to the California's PFL.

The DD results for four alternative measures of food insecurity are shown in Table 4. When further evaluating whether the main treatment effects observed in Table 3 are driven by changes in food security among children or adults, I find that the policy significantly reduced the likelihood of food insecurity among children, while not having an effect on food security level of adults (Panels A and B). The estimates presented in Panels $\mathrm{C}$ and $\mathrm{D}$ are in line with the main findings by showing that California's PFL introduction significantly reduced the distance to both food security thresholds (for the main control group $1=$ all states). Thus, the results in Table 4 provide additional robustness to the study and confirm the policy significantly improved food security levels of households with children in California.

Table 5 shows heterogeneous estimates by poverty level, number of children, and parent's age. Panel A shows that the effects of the PFL law on food security are substantially larger for households below $185 \%$ of the federal poverty line. This is in line with evidence by Winston et al. (2017) who show that, despite having less access to PFL due to lower employment rates, less wealthy families in California value PFL benefits as an important support for both parent and child well-being that allows them

\footnotetext{
${ }_{10}$ The DDD estimates for all three control groups are very similar in terms of magnitude and statistical significance when including state-specific time trends. These results are not included in the paper, but are available upon request.
} 
Table 3 Effect of California's PFL on very low food insecurity (DD and DDD results)

\begin{tabular}{|c|c|c|c|c|c|c|}
\hline & \multicolumn{2}{|c|}{$\begin{array}{l}\text { Control group } 1 \\
\text { (All states) }\end{array}$} & \multicolumn{2}{|c|}{$\begin{array}{l}\text { Control group } 2 \\
\text { (Large states) }\end{array}$} & \multicolumn{2}{|c|}{$\begin{array}{l}\text { Control group } 3 \\
\text { (Neighboring states) }\end{array}$} \\
\hline & (1) & (2) & (3) & (4) & (5) & (6) \\
\hline \multicolumn{7}{|l|}{ Panel A: DD model } \\
\hline Treatment effect & $\begin{array}{l}-0.0220 * * * \\
(0.0037)\end{array}$ & $\begin{array}{l}-0.0229 * * * \\
(0.0033)\end{array}$ & $\begin{array}{l}-0.0208 * * * \\
(0.0043)\end{array}$ & $\begin{array}{l}-0.0201 * * \\
(0.0070)\end{array}$ & $\begin{array}{l}-0.0179 \\
(0.0223)\end{array}$ & $\begin{array}{l}-0.0218 \\
(0.0177)\end{array}$ \\
\hline Observations & 22,236 & & 5563 & & 3253 & \\
\hline \multicolumn{7}{|c|}{ Panel B: DDD model } \\
\hline Treatment effect & $\begin{array}{l}-0.0152 * * * \\
(0.0042)\end{array}$ & $\begin{array}{l}-0.0198 * * * \\
(0.0041)\end{array}$ & $\begin{array}{l}-0.0228 * * * \\
(0.0064)\end{array}$ & $\begin{array}{l}-0.0267 * * * \\
(0.0064)\end{array}$ & $\begin{array}{l}-0.0130 \\
(0.0246)\end{array}$ & $\begin{array}{l}-0.0247 \\
(0.0227)\end{array}$ \\
\hline Observations & 63,808 & & 16,600 & & 9560 & \\
\hline Year fixed effects & $\mathrm{X}$ & $\mathrm{x}$ & $\mathrm{x}$ & $\mathrm{x}$ & $\mathrm{x}$ & $\mathrm{x}$ \\
\hline State fixed effects & $\mathrm{X}$ & $\mathrm{X}$ & $\mathrm{X}$ & $\mathrm{X}$ & $\mathrm{x}$ & $\mathrm{x}$ \\
\hline Controls & & $\mathrm{X}$ & & $\mathrm{X}$ & & $\mathrm{X}$ \\
\hline
\end{tabular}

For control group 1, I use the wild cluster bootstrap procedure with 1000 replications to estimate $p$ values clustered at the state level, as proposed by Cameron et al. (2008). For control groups 2 and 3, I implement a 6-point distribution as introduced Webb (2014). The control variables include age, gender, race, marital status, employment status, completed level of education, the number of children living in the household, annual state unemployment and poverty rates

$* * p<0.01 ; * * * p<0.001$

to partially subsidize time to spend with their newborn children. Furthermore, the magnitude of the treatment effects observed for the low-income group are plausible given the established differences in food security rates across socioeconomic status. Rose et al. (1998) provide evidence that households that are in poverty are 3.5 times more likely to be food insufficient than those above the poverty threshold. Prior work on California's PFL shows that the policy implementation had largest increases in leave taking (Rossin-Slater et al. 2013) and the largest reductions in poverty (Stanczyk 2019) among less advantaged mothers. In line with this, Bana et al. (2018) show that increasing PFL take-up among the least advantaged families may be an important tool to reduce societal inequalities. The results in Table 5 indicate that the PFL implementation contributed toward reducing the gap in very low food security across income groups.

Additionally, Table 5 shows that the policy change had larger effects on food security of families with more than one child and for parents $<30$ years of age. Similar to the findings by poverty status, these results indicate that these families potentially value PFL benefits more given that they have greater need for support around the time of childbirth due to potential financial stress as a result of not receiving paid maternal benefits prior to 2004. The finding that food security of families with more than one child also suggests that PFL provisions provide positive spillover effects to the well-being of older children. 
Table 4 Effect of PFL on food insecurity-alternative outcomes (DD results)

$\begin{array}{lll}\begin{array}{l}\text { Control group 1 } \\ \text { (All states) }\end{array} & \begin{array}{l}\text { Control group 2 } \\ \text { (Large states) }\end{array} & \begin{array}{l}\text { Control group 3 } \\ \text { (Neighboring states) }\end{array} \\ (1) & (2) & \text { (3) }\end{array}$

Panel A: Low/very low food security-adults

$\begin{array}{llll}\text { DD effect } & 0.0024 & 0.0050 & 0.0560 \\ & (0.0064) & (0.0123) & (0.0288)\end{array}$

Panel B: Low/very low food security-children

$\begin{array}{llll}\text { DD effect } & -0.0141^{* *} & -0.0144 * * * & -0.0032 \\ & (0.0057) & (0.0038) & (0.0133)\end{array}$

Panel C: Food insecurity gap-low food security

\begin{tabular}{|c|c|c|c|}
\hline DD effect & $\begin{array}{l}-0.0058 * * \\
(0.0021)\end{array}$ & $\begin{array}{l}-0.0022 \\
(0.0044)\end{array}$ & $\begin{array}{l}0.0078 \\
(0.0119)\end{array}$ \\
\hline
\end{tabular}

Panel D: Food insecurity gap-very low food security

\begin{tabular}{llll} 
DD effect & $-0.0023^{* * *}$ & -0.0019 & $-0.0033^{\dagger}$ \\
Observations & $(0.0006)$ & $(0.0025)$ & $(0.0020)$ \\
Year fixed effects & 22,236 & 5563 & 3253 \\
State fixed effects & $\mathrm{x}$ & $\mathrm{x}$ & $\mathrm{x}$ \\
Controls & $\mathrm{x}$ & $\mathrm{x}$ & $\mathrm{x}$ \\
\hline
\end{tabular}

For control group 1, I use the wild cluster bootstrap procedure with 1000 replications to estimate $p$ values clustered at the state level, as proposed by Cameron et al. (2008). For control groups 2 and 3, I implement a 6-point distribution as introduced Webb (2014). The control variables include age, gender, race, marital status, employment status, completed level of education, the number of children living in the household, annual state unemployment and poverty rates

${ }^{\dagger} p<0.10 ; * * p<0.01 ; * * * p<0.001$

\subsection{Robustness tests}

Table 6 presents estimates from a placebo test that uses artificial treatment dates while analyzing the pre-PFL years 1996-2003. The DD and DDD results for all three control groups show no differential effects of the artificial reform (January 1st, 2000) on very low food security across treatment and control states. While providing evidence that the main estimates in Table 3 are driven by California's PFL introduction, the null results also provide suggestive evidence that there were no differential trends in food security across treatment and control groups before the 2004 policy change. ${ }^{11}$

Figure 1a-c provide results from the three events study models. While the graphs for the first two control groups (all states and large states, Fig. 1a, b) show statistically significant negative effects for the years 1997 and 1998, the graphs provide evidence that there were no differential trends between treatment and control groups in the three years (2001-2003) prior to the policy change. A potential explanation for the lack of parallel trends for the entire period 1996-2003 is the fact that the study

11 The nil effects shown in Table 6 remain unchanged when altering the artificial treatment year to all other years between 1996 and 2003. 
Table 5 Heterogeneous effects of California's PFL on very low food security

\begin{tabular}{|c|c|c|c|c|c|c|}
\hline & \multicolumn{2}{|c|}{$\begin{array}{l}\text { Control group } 1 \\
\text { (All states) }\end{array}$} & \multicolumn{2}{|c|}{$\begin{array}{l}\text { Control group } 2 \\
\text { (Large states) }\end{array}$} & \multicolumn{2}{|c|}{$\begin{array}{l}\text { Control group } 3 \\
\text { (Neighboring states) }\end{array}$} \\
\hline & (1) & (2) & (3) & (4) & $(5)$ & (6) \\
\hline Panel A: poverty & $D D$ & $D D D$ & $D D$ & $D D D$ & $D D$ & $D D D$ \\
\hline Below $185 \%$ FPL & $\begin{array}{l}-0.0458 * * * \\
(0.0085)\end{array}$ & $\begin{array}{l}-0.0316^{* *} \\
(0.0124)\end{array}$ & $\begin{array}{l}-0.0317 * \\
(0.0151)\end{array}$ & $\begin{array}{l}-0.0688^{* * *} \\
(0.0095)\end{array}$ & $\begin{array}{l}-0.0679^{\dagger} \\
(0.0397)\end{array}$ & $\begin{array}{l}-0.0308 \\
(0.0489)\end{array}$ \\
\hline$N$ & 7696 & 19,470 & 1901 & 5378 & 1256 & 3257 \\
\hline Above $185 \%$ FPL & $\begin{array}{l}-0.0137 * * * \\
(0.0025)\end{array}$ & $\begin{array}{l}-0.0173^{* * *} \\
(0.0026)\end{array}$ & $\begin{array}{l}-0.0187^{* *} \\
(0.0070)\end{array}$ & $\begin{array}{l}-0.0104 \\
(0.0058)\end{array}$ & $\begin{array}{l}-0.0084 \\
(0.0052)\end{array}$ & $\begin{array}{l}-0.0252^{* * * *} \\
(0.0046)\end{array}$ \\
\hline$N$ & 12,159 & 36,688 & 2972 & 8935 & 1615 & 5102 \\
\hline \multicolumn{7}{|l|}{ Panel B: \# of children } \\
\hline One child & $\begin{array}{l}-0.0101^{\dagger} \\
(0.0053)\end{array}$ & $\begin{array}{l}-0.0056 \\
(0.0065)\end{array}$ & $\begin{array}{l}-0.0157 \\
(0.0100)\end{array}$ & $\begin{array}{l}-0.0158 * \\
(0.0061)\end{array}$ & $\begin{array}{l}0.0189^{\dagger} \\
(0.0102)\end{array}$ & $\begin{array}{l}0.0077 \\
(0.0255)\end{array}$ \\
\hline$N$ & 8382 & 19,467 & 2065 & 5054 & 1241 & 2893 \\
\hline More than one child & $\begin{array}{l}-0.0303 * * * \\
(0.0045)\end{array}$ & $\begin{array}{l}-0.0282^{* * * *} \\
(0.0049)\end{array}$ & $\begin{array}{l}-0.0243^{* *} \\
(0.0098)\end{array}$ & $\begin{array}{l}-0.0337 * * * \\
(0.0065)\end{array}$ & $\begin{array}{l}-0.0402 * \\
(0.0205)\end{array}$ & $\begin{array}{l}-0.0414 \\
(0.0305)\end{array}$ \\
\hline$N$ & 13,854 & 44,341 & 3498 & 11,546 & 2012 & 6667 \\
\hline \multicolumn{7}{|l|}{ Panel $C$ : parent's age } \\
\hline Less than 30 & $\begin{array}{l}-0.0363^{* * * *} \\
(0.0048)\end{array}$ & $\begin{array}{l}-0.0224 * * * \\
(0.0076)\end{array}$ & $\begin{array}{l}-0.0355^{* * *} \\
(0.0093)\end{array}$ & $\begin{array}{l}-0.0231 * * \\
(0.0066)\end{array}$ & $\begin{array}{l}-0.0563 * \\
(0.0258)\end{array}$ & $\begin{array}{l}-0.0397 \\
(0.0515)\end{array}$ \\
\hline$N$ & 10,586 & 17,986 & 2410 & 4388 & 1519 & 2686 \\
\hline At least 30 & $\begin{array}{l}-0.0148 * * * \\
(0.0042)\end{array}$ & $\begin{array}{l}-0.0134 * * * \\
(0.0045)\end{array}$ & $\begin{array}{l}-0.0097 \\
(0.0055)\end{array}$ & $\begin{array}{l}-0.0212 \\
(0.0134)\end{array}$ & $\begin{array}{l}0.0001 \\
(0.0094)\end{array}$ & $\begin{array}{l}-0.0052 \\
(0.0224)\end{array}$ \\
\hline$N$ & 11,650 & 45,822 & 3153 & 12,212 & 1734 & 6874 \\
\hline
\end{tabular}

For control group 1, I use the wild cluster bootstrap procedure with 1000 replications to estimate $p$ values clustered at the state level, as proposed by

Cameron et al. (2008). For control groups 2 and 3, I implement a 6-point distribution as introduced Webb (2014). All specifications include the full

set of controls, as used in Table 3

${ }^{\dagger} p<0.10 ; * p<0.05 ; * * p<0.01 ; * * * p<0.001$

only has one state that receives the treatment and the relatively small number of observations in the treatment group (between 200 and 300 observations annually). While this is a limitation of the study, the observed nil effects for the three years prior to California's PFL implementation is reassuring for credibility of the DD models. ${ }^{12}$ Both Fig. 1a, b further show evidence for statistically significant negative effects on the likelihood of experiencing very low food security following the PFL introduction when using all and large states as the control group, respectively. It is noticeable that the effects are largest in 2007, suggesting that it takes some time after the policy change before the treatment effects are strongest.

\footnotetext{
12 While the hypothesis that the pre-trend coefficients are jointly equal to 0 is rejected at the $5 \%$ level when using all pre-treatment years (1996-2003) for Fig. 1a, it is not rejected when only using the years 2000-2003.
} 
Table 6 Placebo tests (1996-2003, Policy change 1/1/2000)

\begin{tabular}{llll}
\hline & $\begin{array}{l}\text { Control group 1 } \\
\text { (All states) }\end{array}$ & $\begin{array}{l}\text { Control group 2 } \\
\text { (Large states) }\end{array}$ & $\begin{array}{l}\text { Control group 3 } \\
\text { (Neighboring states) }\end{array}$ \\
\hline $\begin{array}{l}\text { Panel A: DD model } \\
\text { Very low food security }\end{array}$ & 0.0019 & $(2)$ & $(3)$ \\
\hline Observations & $(0.0049)$ & -0.0039 & -0.0010 \\
Panel B: DDD model & 22,350 & $(0.0107)$ & $(0.0090)$ \\
Very low food security & 0.0034 & 3557 & 2045 \\
& $(0.0041)$ & & -0.0288 \\
Observations & 40,390 & 0.0014 & $(0.0138)$ \\
Year fixed effects & $\mathrm{x}$ & $(0.0082)$ & 6027 \\
State fixed effects & $\mathrm{x}$ & 10,578 & $\mathrm{x}$ \\
Controls & $\mathrm{x}$ & $\mathrm{x}$ & $\mathrm{x}$ \\
\hline
\end{tabular}

For control group 1, I use the wild cluster bootstrap procedure with 1000 replications to estimate $p$ values clustered at the state level, as proposed by Cameron et al. (2008). For control groups 2 and 3, I implement a 6-point distribution as introduced Webb (2014). The control variables include age, gender, race, marital status, employment status, completed level of education, the number of children living in the household, annual state unemployment and poverty rates

${ }^{\dagger} p<0.10 ; * p<0.05 ; * * p<0.01 ; * * * p<0.001$

Table 7 provides results obtained from estimating the DD specification introduced by Mora and Reggio (2019), which incorporates a number of additional DD assumptions based on the number of pre-treatment periods and allows estimating the treatment effect for this family of alternative parallel trends assumptions. For all three control groups, I find statistically significant reductions in the likelihood of experiencing very low food security following the PFL implementation. The fact that the magnitude of the effects is similar between the standard DD model and the two-step Mora and Reggio (2019) model provides further suggestive evidence for the validity of the main DD analysis used in this study.

Table 8 presents DD and DDD estimates for the effects of the policy change on a range of time-varying observable characteristics that are used as controls in the main specifications. The results show that only two of the twelve estimates are statistically significant (state unemployment rates in the DD model and age in the DDD model). The lack of significance for ten of the twelve treatment effects suggests that the 2004 PFL implementation was uncorrelated with other time-varying determinants of food security. Finally, estimating an interaction term between a "non-California" dummy and a linear time trend while analyzing the pre-policy period (1999-2003), the coefficient of the interaction term is small and statistically insignificant $(0.0020$ percentage points). This lends support for the validity of the DD parallel trends assumption provides additional suggestive evidence confirming that food security trends did not differ between California and the other states prior to $2004 .^{13}$

$\overline{13}$ The results for this additional robustness check are not shown in the paper, but are available upon request. 
a

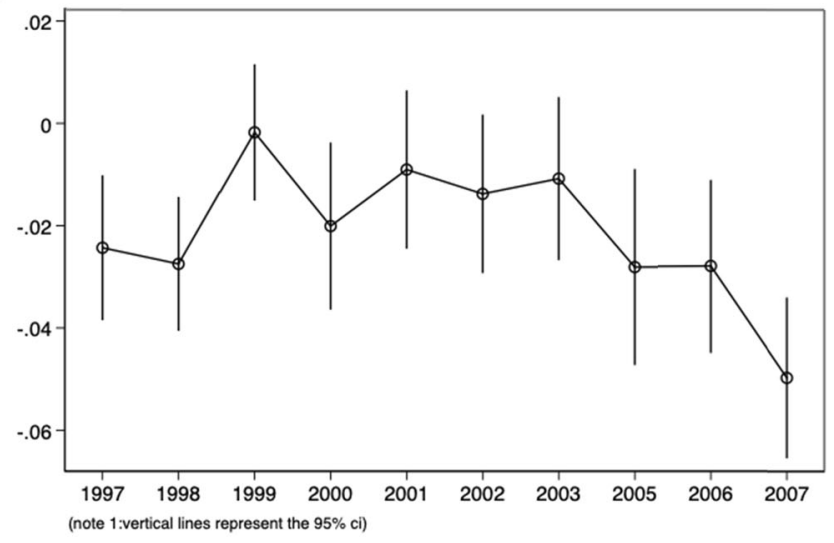

b

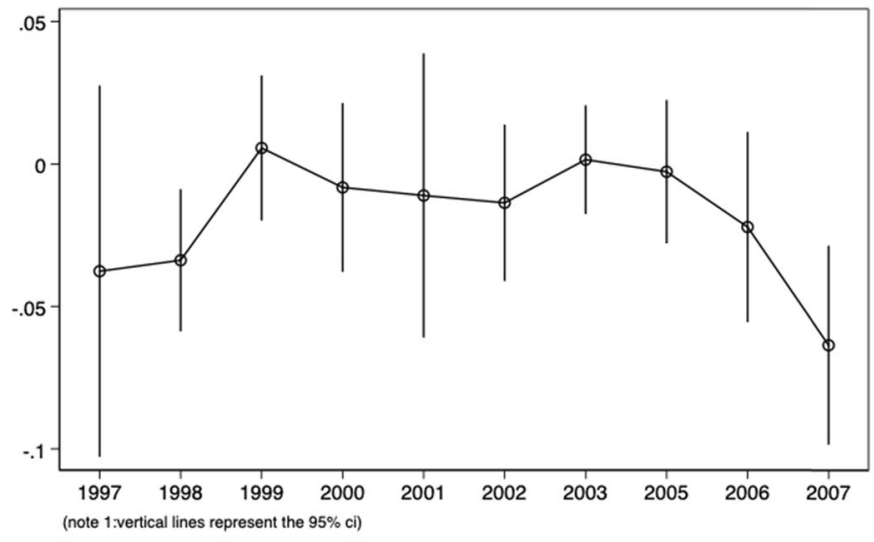

C

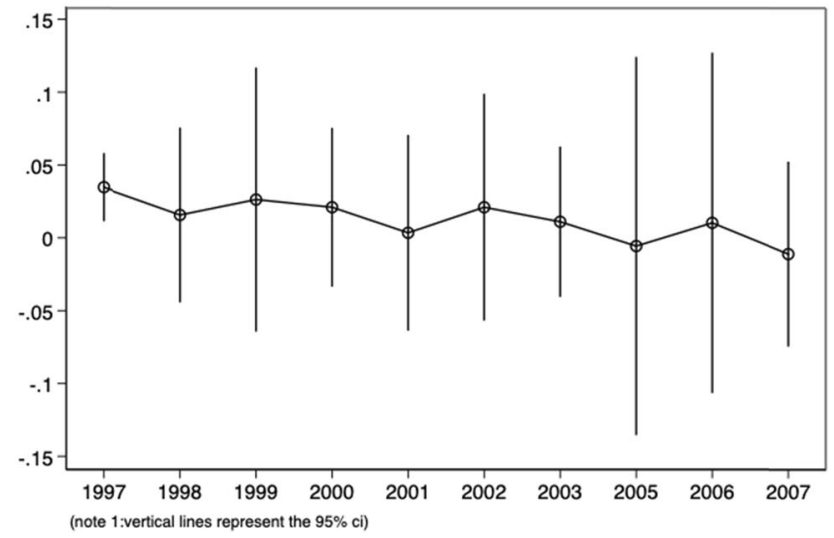

Fig. 1 Event study results—very low food security. a Event study—controls group 1 (All states). b Event study—control group 2 (Large states). c Event study—control group 3 (Neighboring states) 
Table 7 Alternative DD model (Mora and Reggio 2019)

$\begin{array}{lll}\begin{array}{l}\text { Control group 1 } \\ \text { (All states) }\end{array} & \begin{array}{l}\text { Control group 2 } \\ \text { (Large states) }\end{array} & \begin{array}{l}\text { Control group 3 } \\ \text { (Neighboring states) }\end{array} \\ (1) & \text { (2) } & \text { (3) }\end{array}$

\begin{tabular}{llll}
\hline Panel A: DD model & & & \\
Very low food security & $0.0194^{* *}$ & $-0.0209^{*}$ & $-0.0223^{\dagger}$ \\
& $(0.0076)$ & $(0.0089)$ & $(0.0126)$ \\
Observations & 22,236 & 5563 & 3253 \\
Year fixed effects & $\mathrm{x}$ & $\mathrm{x}$ & $\mathrm{x}$ \\
State fixed effects & $\mathrm{x}$ & $\mathrm{x}$ & $\mathrm{x}$ \\
Controls & $\mathrm{x}$ & $\mathrm{x}$ & $\mathrm{x}$ \\
\hline
\end{tabular}

The control variables include age, gender, race, marital status, employment status, completed level of education, the number of children living in the household, annual state unemployment and poverty rates ${ }^{\dagger} p<0.10 ; * p<0.05 ; * * p<0.01$

Table 8 Effect of PFL on selected control variables (Control group 1)

\begin{tabular}{|c|c|c|c|c|c|c|c|}
\hline & Age & Children in $\mathrm{HH}$ & HS degree & $\begin{array}{l}\text { More than } \\
\text { HS degree }\end{array}$ & White & $\begin{array}{l}\text { Maximum } \\
\text { food stamps }\end{array}$ & State UR \\
\hline \multicolumn{8}{|c|}{ Panel A: DD model } \\
\hline DD estimate & $\begin{array}{l}0.1476 \\
(0.1643)\end{array}$ & $\begin{array}{l}-0.0112 \\
(0.0228)\end{array}$ & $\begin{array}{l}0.0083 \\
(0.0092)\end{array}$ & $\begin{array}{l}-0.0093 \\
(0.0086)\end{array}$ & $\begin{array}{l}0.002 \\
(0.0064)\end{array}$ & $\begin{array}{l}-0.6132 \\
(0.7345)\end{array}$ & $\begin{array}{l}-0.2211 \\
(0.1114)\end{array}$ \\
\hline Observations & 22,236 & & & & & & \\
\hline \multicolumn{8}{|c|}{ Panel B: DDD model } \\
\hline $\begin{array}{l}\text { DDD } \\
\text { estimate }\end{array}$ & $\begin{array}{l}0.5215 \\
(0.1982)\end{array}$ & $\begin{array}{l}-0.0205 \\
(0.0252)\end{array}$ & $\begin{array}{l}-0.0038 \\
(0.0088)\end{array}$ & $\begin{array}{l}0.0002 \\
(0.0078)\end{array}$ & $\begin{array}{l}-0.0097 \\
(0.0065)\end{array}$ & $\begin{array}{l}0.0944 \\
(0.0462)\end{array}$ & $\begin{array}{l}0.0279 \\
(0.0252)\end{array}$ \\
\hline Observations & 63,808 & & & & & & \\
\hline $\begin{array}{l}\text { Year fixed } \\
\text { effects }\end{array}$ & $\mathrm{x}$ & $\mathrm{x}$ & $\mathrm{x}$ & $\mathrm{x}$ & $\mathrm{x}$ & $\mathrm{x}$ & $\mathrm{x}$ \\
\hline $\begin{array}{l}\text { State fixed } \\
\text { effects }\end{array}$ & $\mathrm{x}$ & $\mathrm{x}$ & $\mathrm{x}$ & $\mathrm{x}$ & $\mathrm{x}$ & $\mathrm{x}$ & $\mathrm{x}$ \\
\hline Controls & $\mathrm{x}$ & $\mathrm{x}$ & $\mathrm{x}$ & $\mathrm{x}$ & $\mathrm{x}$ & $\mathrm{x}$ & $\mathrm{x}$ \\
\hline
\end{tabular}

The estimates are obtained using separate specifications. I use the wild cluster bootstrap procedure with 1000 replications to estimate $p$ values clustered at the state level, as proposed by Cameron et al. (2008) ${ }^{\dagger} p<0.10 ; * p<0.05 ; * * p<0.01 ; * * * p<0.001$

Recent work by MacKinnon and Webb (2020) shows that different variants of the wild cluster bootstrap can yield standard errors that lead either to over- or underrejecting the null when there are few treated clusters. The authors propose a randomization inference (RI) framework to explicitly for DD when there are few treated clusters. I follow the authors approach to check whether the main DD results hold up to this RI framework. The results are shown in Appendix Table 9. For all three control groups, the RI estimates show that the PFL implementation led to a 
statistically significant reduction in the likelihood of very low food security. The results in Table A1 provide further evidence for the validity of the main DD analysis.

Finally, a concern for the validity of the DD and DDD estimates in this study would be if changes in the Special Supplemental Nutrition Program for Women, Infants, and Children (WIC), which targets breastfeeding women and mothers of children under five, differed between California and the control states. While California has had the highest share of all WIC participants in the country throughout the years of the study, Appendix Table 10 shows that the share of all total WIC agencies and the share of total WIC participants remained similar in California and the three control groups between 1996 and 2006.

\section{Conclusions}

This study adds to previous work on California's PFL program, the first statewide law that allowed parents to receive paid maternal benefits following the birth of their child. While researchers have shown that the policy introduction improved labor market outcomes as well as the health of children and mothers, this analysis evaluates the impact of the law on food security of affected households. By finding that California's PFL program reduced the likelihood of households experiencing very low food insecurity rates by 2.29 percentage points and reduced child food insecurity by 1.41 percentage points, the analysis provides evidence for additional positive effects of paid family leave programs on well-being. The observed effects of PFL on food insecurity are in line with previous studies providing evidence of potentially unintended benefits of safety net programs on food security. Moellman (2020) finds that the ACA Medicaid expansion reduced the incidence of very low food security by between 2.7 and 4.6 percentage points, while Schmidt et al. (2016) show that $\$ 1000$ in safety net benefits reduces the incidence of food insecurity by 1.1 percentage points.

While proposals to introduce a national paid maternity leave program in the U.S. have been presented to Congress every year since 2013 and there has been much public discussion on the issue, no such policies have yet been implemented. The positive impacts of California's PFL on the well-being of families shown by this study and others suggest that other states could also benefit from adapting similar policies. With three additional states having announced their implementation of PFL laws between 2020 and 2023 (D.C., Connecticut, and Oregon), bringing the total number of states with PFL laws up to nine, research on the impacts of these programs could potentially shape a national program in the near future. This study contributes to some previous work that have improved the understanding of the intended and unintended effects of PFL laws. Adding to findings of reduced poverty (Stanczyk 2019) and improved health outcomes of mothers and infants (Bullinger 2019; Lichtman-Sadot and Pillay Bell 2017; Pihl and Basso 2019), the results of this study indicate that PFL policies can also reduce food insecurity levels of families following the birth of a child.

A limitation of the study is that the food insecurity questions used for this study cover the period 12 months prior to the survey, whereas the families in the sample have children $<1$ year of age. Due to the fact that I do not have information on the age of the infants in month, the estimates of the analysis might represent lower bound effects of PFL laws on food insecurity. Additionally, as mentioned throughout the 
paper, the DD and DDD analysis assumes that the implementation of the PFL was uncorrelated with other time-varying determinants of food insecurity. While my analysis controls for changes in the generosity of food stamps and robustness checks provide suggestive evidence that the effects are robust to potential confounders, this does not imply that the estimates are still not slightly influenced by other changes occurring at the time of the study. For example, differences in disability insurance (DI) uptake during the period of the study could lead to the fact that results shown in this study are composite effects of both FPL and DI benefit programs. While my DD and DDD remain unchanged when including controls for state-level changes in DI insurance (coverage and monthly payments), this does not guarantee that DI still influence the findings of the study. Finally, future work on PFL laws should examine whether individuals decide to relocate to take advantage of benefits.

\section{Compliance with ethical standards}

Conflict of interest The author declares that he has no conflict of interest.

Publisher's note Springer Nature remains neutral with regard to jurisdictional claims in published maps and institutional affiliations.

Open Access This article is licensed under a Creative Commons Attribution 4.0 International License, which permits use, sharing, adaptation, distribution and reproduction in any medium or format, as long as you give appropriate credit to the original author(s) and the source, provide a link to the Creative Commons license, and indicate if changes were made. The images or other third party material in this article are included in the article's Creative Commons license, unless indicated otherwise in a credit line to the material. If material is not included in the article's Creative Commons license and your intended use is not permitted by statutory regulation or exceeds the permitted use, you will need to obtain permission directly from the copyright holder. To view a copy of this license, visit http://creativecommons.org/licenses/by/4.0/.

\section{Appendix}

\section{Food Insecurity Questions:}

1. "(I/We) worried whether (my/our) food would run out before (I/we) got money to buy more". Was that often true, sometimes true, or never true for (you/your household) in the last 12 months?

2. "The food that (I/we) bought just didn't last, and (I/we) didn't have money to get more". Was that often, sometimes, or never true for (you/your household) in the last 12 months?

3. "(I/we) couldn't afford to eat balanced meals". Was that often, sometimes, or never true for (you/your household) in the last 12 months?

4. In the last 12 months, since last (name of current month), did (you/you or other adults in your household) ever cut the size of your meals or skip meals because there wasn't enough money for food?

"Yes" (go to question 5), "No" (skip question 5), or "Do not know" (skip question 5)

5. How often did this happen-almost every month, some months but not every month, or in only 1 or 2 months? 
6. In the last 12 months, did you ever eat less than you felt you should because there wasn't enough money for food?

"Yes", "No", or "Do not know"

7. In the last 12 months, were you every hungry but didn't eat because there wasn't enough money for food?

"Yes", "No", or "Do not know"

8 . In the last 12 months, did you lose weight because there wasn't enough money for food?

"Yes", "No", or "Do not know"

9. In the last 12 months, did (you/you or other adults in your household) ever not eat for a whole day because there wasn't enough money for food?

"Yes" (go to question 10), "No" (skip question 10), or "Do not know” (skip question 10)

10. How often did this happen-almost every month, some months but not every month, or in only 1 or 2 months?

11. "(I/we) relied on only a few kinds of low-cost food to feed (my/our) child/the children) because (I was/we were) running out of money to buy food". Was that often, sometimes, or never true for (you/your household) in the last 12 months?

12. "(I/We) couldn't feed (my/our) child/the children) a balanced meal, because (I/ we) couldn't afford that". Was that often, sometimes, or never true for (you/your household) in the last 12 months?

13. "(My/Our child was/The children were) not eating enough because (I/we) just couldn't afford enough food". Was that often, sometimes, or never true for (you/your household) in the last 12 months?

14. In the last 12 months, since (current month) of last year, did you ever cut the size of (your child's/any of the children's) meals because there wasn't enough money for food?

"Yes", "No", or "Do not know"

15. In the last 12 months, did (CHILD'S NAME/any of the children) ever skip meals because there wasn't enough money for food?

"Yes" (go to question 16), "No" (skip question 16), or "Do not know" (skip question 16)

16. How often did this happen-almost every month, some months but not every month, or in only 1 or 2 months?

17. In the last 12 months, (was your child/were the children) ever hungry but you just couldn't afford more food?

"Yes", "No", or "Do not know"

18. In the last 12 months, did (your child/any of the children) ever not eat for a whole day because there wasn't enough money for food?

"Yes", "No", or "Do not know"

Table 9

Table 10 
Table 9 Randomization inference-DD results

\begin{tabular}{|c|c|c|c|c|c|c|}
\hline & \multicolumn{2}{|c|}{$\begin{array}{l}\text { Control group } 1 \\
\text { (All states) }\end{array}$} & \multicolumn{2}{|c|}{$\begin{array}{l}\text { Control group } 2 \\
\text { (Large states) }\end{array}$} & \multicolumn{2}{|c|}{$\begin{array}{l}\text { Control group } 3 \\
\text { (Neighboring states) }\end{array}$} \\
\hline & (1) & (2) & (3) & (4) & (5) & (6) \\
\hline \multicolumn{7}{|l|}{ DD model } \\
\hline Treatment effect & -0.0229 & & -0.0242 & & -0.0214 & \\
\hline Baseline DD $p$ value & 0.0000 & & 0.0450 & & 0.2870 & \\
\hline Randomization inference $p$ value & & 0.0156 & & 0.0500 & & 0.0499 \\
\hline Observations & 22,236 & & 5563 & & 3253 & \\
\hline Year fixed effects & $\mathrm{x}$ & & $\mathrm{x}$ & & $\mathrm{x}$ & \\
\hline State fixed effects & $\mathrm{x}$ & & $\mathrm{x}$ & & $\mathrm{x}$ & \\
\hline Controls & $\mathrm{x}$ & & $\mathrm{x}$ & & $\mathrm{x}$ & \\
\hline
\end{tabular}

Table 10 Changes to WIC program (1996-2006)

\begin{tabular}{lclll}
\hline & California & $\begin{array}{l}\text { Control group 1 } \\
\text { (All states) }\end{array}$ & $\begin{array}{l}\text { Control group 2 } \\
\text { (Large states) }\end{array}$ & $\begin{array}{l}\text { Control group 3 } \\
\text { (Neighboring states) }\end{array}$ \\
\hline $\begin{array}{l}\text { Panel A: \% of all WIC agencies } \\
1996\end{array}$ & & & \\
1998 & 3.78 & 96.22 & 11.80 & 5.86 \\
2000 & 3.81 & 96.19 & 11.94 & 5.86 \\
2002 & 3.69 & 96.31 & 11.71 & 5.74 \\
2004 & 3.74 & 96.26 & 11.65 & 5.77 \\
2006 & 3.71 & 96.29 & 11.22 & 5.88 \\
Panel B: \% of all WIC participants & & 13.04 & 7.11 \\
1996 & 15.16 & 84.84 & & \\
1998 & 16.75 & 83.25 & 24.75 & 5.10 \\
2000 & 17.22 & 82.78 & 24.00 & 5.34 \\
2002 & 17.51 & 82.49 & 24.32 & 5.62 \\
2004 & 16.69 & 83.31 & 24.52 & 6.14 \\
2006 & 16.78 & 83.22 & 25.22 & 5.95 \\
\hline
\end{tabular}

Data are obtained from semi-annual reports "WIC Participant and Program Characteristics" by the U.S. Department of Agriculture

\section{References}

Anderson, P. M., Butcher, K. F., Hoynes, H. W., \& Whitmore Schanzenbach, D. (2016). Beyond income: What else predicts very low food security among children? Southern Economic Journal, 82(4), 1078-1105.

Bailey, M.J., Byker, T.S., Patel, E., \& Ramnath, S. (2019). The Long-Term Effects of California's 2004 Paid Family Leave Act on Women's Careers: Evidence from US Tax Data. National Bureau of Economic Research, 26416. https://www.nber.org/papers/w26416.

Bana, S., Bedard, K., \& Rossin-Slater, M. (2018). Trends and Disparities in Leave Use under California's Paid Family Leave Program: new Evidence from Administrative Data. AEA Papers and Proceedings, 108, 388-391. 
Baum, C. L., \& Ruhm, C. (2016). The effects of paid family leave in california on labor market outcomes. Journal of Policy Analysis and Management, 35(2), 333-356.

Bhattacharya, J., Currie, J., \& Haider, S. (2004). Poverty, Food Insecurity, and Children Nutritional Outcomes in Children and Adults. Journal of Health Economics, 23(4), 839-862.

Bickel, G., Nord, M., Price, C., Hamilton, W., \& Cook, J. (2000). Guide to Measuring Household Food Security. Alexandria, VA: United States Department of Agriculture.

Bullinger, L. R. (2019). The effect of paid family leave on infant and parental health in the United States. Journal of Health Economics, 66, 101-116.

Byker, T. S. (2016). Paid parental leave laws in the united states: does short-duration leave affect women's labor-force attachment? American Economic Review: Papers \& Proceedings, 106(5), 242-246.

Cameron, A. C., Gelbach, J. B., \& Miller, D. L. (2008). Bootstrap-based improvements for inference with clustered errors. Review of Economics and Statistics, 90(3), 414-427.

Chilton, M. M., Rabinowich, J. R., \& Woolf, N. H. (2014). Very low food security in the usa linked with exposure to violence. Public Health Nutrition, 17(1), 73-82.

Coleman-Jensen, A., Rabbitt, M.P., Gregory, C., Singh, A. (2015). Household Food Security in the United States in 2014. Report No. 194, Washington, DC:Economic Research Service, U.S. Department of Agriculture.

Das, T., \& Polachek, S. W. (2015). Unanticipated effects of California's paid family leave program. Contemporary Economic Policy, 33(4), 619-636.

Dutta, I., Gundersen, C. (2007). Measures of Food Insecurity at the Household Level. In Food Security Indicators, Measurement, and the Impact of Trade Openness: Series: WIDER Studies in Development Economics. Oxford: Oxford University Press.

Gundersen, C. (2008). Measuring the extent, depth, and severity of food insecurity: an application to American Indians in the USA. Journal of Population Economics, 21(1), 191-215.

Gundersen, C., \& Kreider, B. (2008). Food stamps and food insecurity: What can be learned in the presence of non-classical measurement error? Journal of Human Resources, 43(2), 352-382.

Gundersen, C., \& Kreider, B. (2009). Bounding the effects of food insecurity on children's health outcomes. Journal of Health Economics, 28(5), 971-983.

Gundersen, C., Kreider, B., \& Pepper, J. (2011). The economics of food insecurity in the United States. Applied Economic Perspectives and Policy, 33(3), 281-303.

Gundersen, C., \& Oliveira, V. (2001). The food stamp program and food insufficiency. American Journal of Agricultural Economics, 84(3), 875-887.

Gundersen, C., \& Ziliak, J. P. (2015). Food insecurity and health outcomes. Health Affairs, 34(11), 1830-1839.

Han, W.-J., Ruhm, C., \& Waldfogel, J. (2009). Parental leave policies and parents' employment and leavetaking. Journal of Policy Analysis and Management, 28(1), 29-54.

Huang, J., Kim, Y., \& Birkenmaier, J. (2015). Unemployment and household food hardship in the economic recession. Public Health Nutrition, 19(3), 511-519.

Kamerman, S. B. (2006). Parental Leave Policies: the Impact on Child Well-Being. In P. Moss \& M. O'Brien (Eds), International Review of Leave Policies and Related Research 2006 (pp. 16-21). London, UK: Department of Trade and Industry. Accessed on 3 July, 2019.

Kreider, B., Pepper, J. V., Gundersen, C., \& Jolliffe, D. (2012). Identifying the Effects of SNAP (Food Stamps) on Child Health Outcomes When Participation Is Endogenous and Misreported. Journal of the American Statistical Association, 107(49), 958-975.

Lenhart, O. (2019). The effects of income on health: new evidence from the earned income tax credit. Review of Economics of the Household, 17(2), 377-410.

Lichtman-Sadot, S., \& Pillay Bell, N. (2017). Child health in elementary school following california's paid family leave program. Journal of Policy Analysis and Management, 36(4), 790-827.

MacKinnon, J.G., Webb, M.D. (2020). Randomization Inference for Difference-in-Differences with Few Treated Clusters. Journal of Econometrics (forthcoming). https://doi.org/10.1016/j.jeconom.2020.04.024.

McGranahan, L., Schanzenbach, D.W. (2013). The Earned Income Tax Credit and Food Consumption Patterns. Federal Reserve Bank of Chicago Working November 2013, Paper No. 2013-2014. https:// www.chicagofed.org/publications/working-papers/2013/wp-14. Accessed 20 June 2019.

Moellman, N. (2020). Healthcare and Hunger: effects of the ACA medicaid expansion on food insecurity in America. Applied Economic Perspectives and Policy, 42(2), 168-186.

Mora, R., \& Reggio, I. (2019). Alternative diff-in-diffs estimators with several pretreatment periods. Econometric Reviews, 38(5), 465-486.

Mykerezi, E., \& Mills, B. (2010). The impact of food stamp program participation on household food insecurity. American Journal of Agricultural Economics, 92(5), 1379-1391. 
Nord, M. (2007). Characteristics of Low-Income Households with Very Low Food Security: an Analysis of the USDA GPRA Food Security Indicator. U.S. Department of Agriculture, Washington DC, Economic Research Service, EIB No. 25.

Nord, M. (2009). Food Insecurity in Households with Children: prevalence, Severity, and Household Characteristics. U.S. Department of Agriculture, Washington DC, Economic Research Service, EIB No. 56.

Nord, M., Bickel, G. (2002). Children's Food Security in U.S. Households, 1995-99. Washington, DC: United States Department of Agriculture, Economic Research Service: Food Assistance and Nutrition Report No. 25.

Nord, M., Coleman-Jensen, A., \& Gregory, C. (2014). Prevalence of U.S. Food Insecurity is Related to Changes in Unemployment, Inflation, and the Price of Food. Washington DC: U.S. Department of Agriculture, Economic Research Service Report No. 167.

Nord, M., Golla, A.M. (2009). Does SNAP Decrease Food Insecurity? Untangling the Self-Selection Effect. U.S. Department of Agriculture, Washington DC, Economic Research Service Research Report EIB No. 85.

Nord, M., Prell, M. (2011). Food Security Improved Following the 2009 ARRA Increase in SNAP Benefits. U.S. Department of Agriculture, Washington DC, Economic Research Service, Economic Research Report EIB No. 116.

OECD (2019). OECD Family Database. http://www.oecd.org/els/family/database.htm.

Pihl, A. M., \& Basso, G. (2019). Did California Paid Leave Impact Infant Health? Journal of Policy Analysis and Management, 38(1), 155-180.

Ratcliffe, C., McKernan, S. M., \& Zhang, S. (2011). How much does the supplemental nutrition assistance program reduce food insecurity? American Journal of Agricultural Economics, 93(4), 1082-1098.

Reis, M. (2012). Food insecurity and the relationship between household income and children's health and nutrition in Brazil. Health Economics, 21, 405-427.

Rose, D., Gundersen, C., \& Oliveira, V. (1998). Socio-Economic Determinants of Food Insecurity in the United States: evidence from the SIPP and CSFII Datasets. U.S. Department of Agriculture, Washington DC, Food and Rural Economics Division, Economic Research Service. Technical Bulletin No. 1869.

Rossin-Slater, M., Ruhm, C., \& Waldfogel, J. (2013). The effects of California's paid family leave program on mothers' leave-taking and subsequent labor market outcomes. Journal of Policy Analysis and Management, 32(2), 224-245.

Ruhm, C. (1998). Parental leave and child health. Journal of Health Economics, 19(6), 931-960.

Schanzenbach, D.W., Bauer, L., \& Nantz, G. (2016). Twelve Facts about Food Insecurity and SNAP. (pp.1-20) The Hamilton Project, Washington DC. Economic Facts, April 2016.

Schmidt, L., Shore-Sheppard, L., \& Watson, T. (2016). The effect of safety-net programs on food insecurity. The Journal of Human Resources, 51(3), 589-614.

Schwarzenberg, S. J., \& Georgieff, M. K. (2018). Advocacy for improving nutrition in the first 1000 days to support childhood development and adult health. Pediatrics, 141(2), 1-12.

Stanczyk, A. (2019). Does paid family leave improve household economic security following a birth? Evidence from California. Social Service Review, 93(2), 262-304.

U.S. Bureau of Labor Statistics (2018). National Compensation Survey: employee Benefits in the United States, March 2018 (Tables 16 and 32). U.S. Bureau of Labor Statistics and U.S. Department of Labor. https://www.bls.gov/ncs/ebs/benefits/2018/employee-benefits-in-the-united-states-march-2018.pdf. Accessed 27 July 2019.

Webb, M.D. (2014). Reworking Wild Bootstrap Based Inference for Clustered Errors. Working Paper 1315, Queen's University, Department of Economics, Kingston Ontario, Canada.

Winston, P., Pihl, A., Groves, L., Campbell, C., Coombs, E., \& Wolf, S. (2017). Exploring the Relationship between Paid Family Leave and the Well-Being of Low-Income Families: lessons from California. U.S. Department of Health and Human Services, Office of the Assistant Secretary for Planning and Evaluation. https://aspe.hhs.gov/system/files/pdf/255486/PFL.pdf.

Ziliak, J., Gundersen, C., \& Figlio, D. (2003). Food stamp caseloads over the business cycle. Southern Economic Journal, 69(4), 903-919. 